\title{
Erratum to: Nutritional management of a patient with obesity and pulmonary embolism: a case report
}

\author{
Marria Luisa Fonte ${ }^{1}$, Lauren Fiechtner ${ }^{2}$, Matteo Manuelli ${ }^{1 *}$ and Hellas Cena ${ }^{1}$
}

\section{Erratum}

After the publication of this article [1] it was noticed that there was a misspelling in the author name Laura Fiechtner where the ' $t$ ' was missing.

The original article was corrected.

The publisher apologises for this error.

\begin{abstract}
Author details
${ }^{1}$ Department of Public Health, Experimental and Forensic Medicine, Unit of Human Nutrition, University of Pavia, Via Bassi, 21, 27100 Pavia, PV, Italy. ${ }^{2}$ Department of Pediatrics, Division of Pediatrics Gl and General Academic Pediatrics Mass General Hospital for Children, Boston, Massachussets, USA.
\end{abstract}

Received: 19 January 2017 Accepted: 19 January 2017

Published online: 01 February 2017

\section{Reference}

1. Fonte ML, Fiechtner L, Manuelli M, Cena H. Nutritional management of a

patient with obesity and pulmonary embolism: a case report. Nutr J.

2016;15:90.

\footnotetext{
*Correspondence: matteo.manuelli@unimi.it

${ }^{1}$ Department of Public Health, Experimental and Forensic Medicine, Unit of

Human Nutrition, University of Pavia, Via Bassi, 21, 27100 Pavia, PV, Italy

Full list of author information is available at the end of the article
} 